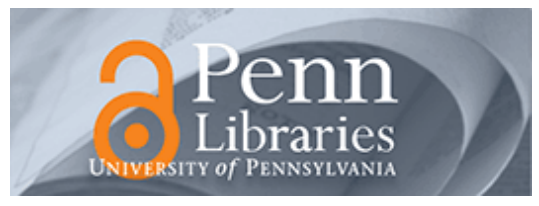

University of Pennsylvania

ScholarlyCommons

Marketing Papers

Wharton Faculty Research

1994

\title{
How Serious are Methodological Issues in Surveys? A Reexamination of the Clarence Thomas Polls
}

\author{
J. Scott Armstrong \\ University of Pennsylvania, armstrong@wharton.upenn.edu \\ Fred Collopy \\ Case Western Reserve University
}

Follow this and additional works at: https://repository.upenn.edu/marketing_papers

Part of the Marketing Commons

\section{Recommended Citation}

Armstrong, J. S., \& Collopy, F. (1994). How Serious are Methodological Issues in Surveys? A Reexamination of the Clarence Thomas Polls. Retrieved from https://repository.upenn.edu/ marketing_papers/216

This paper is posted at ScholarlyCommons. https://repository.upenn.edu/marketing_papers/216

For more information, please contact repository@pobox.upenn.edu. 


\title{
How Serious are Methodological Issues in Surveys? A Reexamination of the Clarence Thomas Polls
}

\author{
Abstract \\ Opinion polling procedures allow for reasonable inferences about attitude changes. We examined this \\ contention using surveys about the nomination of Clarence Thomas. In this situation, prior theory allowed \\ us to predict the direction of changes, surveys had been conducted by a number of organizations, and \\ substantial information was available about the methodology used in the surveys. As a result we \\ concluded that the deteriorating opinions of Thomas were real. \\ Disciplines \\ Business | Marketing
}




\title{
How Serious are Methodological Issues in Surveys? A Reexamination of the Clarence Thomas Polls
}

\author{
J. Scott Armstrong \\ The Wharton School \\ University of Pennsylvania \\ Philadelphia, PA 19104 \\ Phone: $215-898-5087$ \\ Fax: 215-898-2534 \\ e-mail: armstrongj@wharton.upenn.edu \\ Fred Collopy \\ The Weatherhead School of Management \\ Case Western Reserve University \\ Cleveland, Ohio 44106 \\ Phone: 216-368-2048 \\ Fax: 216-368-4776 \\ e-mail: flc2@po.cwru.edu
}

1994

\begin{abstract}
Opinion polling procedures allow for reasonable inferences about attitude changes. We examined this contention using surveys about the nomination of Clarence Thomas. In this situation, prior theory allowed us to predict the direction of changes, surveys had been conducted by a number of organizations, and substantial information was available about the methodology used in the surveys. As a result we concluded that the deteriorating opinions of Thomas were real.
\end{abstract}

Polls suggest that there was a change of opinions about Clarence Thomas in the year following the confirmation hearings that put him on the Supreme Court (Rucinski 1993). In 15 polls conducted in 1991, an average of $51 \%$ of the respondents were pro-Thomas. In contrast, only $37 \%$ of the respondents were pro-Thomas in three 1992 surveys. $^{1}$

1 We used unweighted averages throughout the paper. 
Did the year-after polls reflect a real change in public perception of Anita Hill's charges? Rucinski (1993) suggested that the differences might have been due largely to methodological issues, such as nonresponse bias, and she questions whether the estimates in the 1991 polls were good enough to draw conclusions.

Rucinski highlighted some of the difficulties in interpreting the polls due to the varied quality of disclosure. We agree with her suggestions that better polling procedures and fuller disclosure of survey methodologies are desirable. Evidence for the value of fuller disclosure has also been provided by Buchanan (1986) and by Lau (1994). But Rucinski's work raises some questions regarding polling practices that are potentially more fundamental. If, given current procedures, one cannot use polls such as these to draw inferences and to make comparisons over time, then survey research would lose much of the value it is perceived to have. This is particularly so because her concern is raised in a context involving 18 polls by leading survey organizations. If conclusions cannot be made under these conditions, then there are few situations that would allow such analyses of change.

The analysis by Rucinski raises doubts about some important methodological issues in the Hill-Thomas surveys. We do not agree that this means that the polling results cannot be interpreted. Instead, we believe that it is possible to interpret the polls when they are examined in the context of expectations about attitude change. We also examine how each of the methodological issues would affect polling results.

\section{Expectations About Attitude Change}

It is difficult to provide plausible explanations to suggest improvements in the attitudes towards Thomas, although it is possible that the role of a Supreme Court judge or exemplary behavior as a jurist might help in this regard. It is easier to propose explanations that attitudes would deteriorate over time. One obvious explanation is that additional information has come out since the confirmation. (For a summary, see Mayer and Abramson 1994). In addition, one would expect that the full effects of the Anita Hill testimony may not have been reflected in the earlier polls. We discuss this latter possibility at length here.

At the time of the confirmation hearings, many people had an inconsistent set of beliefs. Specifically, respondents who desired that Thomas receive the appointment were presented with evidence that Thomas may not have told the truth. Of these, some believed that the evidence was authentic. Many of them may also have believed that it would be improper for a person who lied in Senate hearings to be appointed to the Supreme Court. 
Confirmation of a nominee is essentially a personnel selection problem. Research on the personnel selection problem suggests that recruiters typically make rapid decisions, often in a few minutes (Webster, 1964).

Furthermore, they are not fully aware of how they make the decision. Once an opinion is reached, they tend to ignore disconfirming evidence. Research also suggests that people typically are resistant to new evidence that refutes their beliefs. Instead, in the near-term disconfirming evidence often strengthens original beliefs. Surprisingly, stronger disconfirming evidence sometimes produces greater resistance to change (Batson, 1975). Consider the October 1991 "weekend hearings" on the nomination of Clarence Thomas. Evidence was presented that disconfirmed the beliefs of those favoring Thomas, but this appeared to have no impact on the opinions of the Senate Committee or of Senators in general (New York Times, October 15, 1991, p. 1).

Though disconfirming evidence tends to be resisted initially, it sometimes has a long-term impact because people prefer to reduce dissonance in their beliefs (see Cialdini, 1993, Chapter 3, for a summary of evidence on this phenomena). For the Thomas appointment, some might do this by changing their opinions about Anita Hill's credibility and deciding that Thomas told the truth. Others, however, might decide that it was a mistake to appoint Thomas. As there are no obvious reasons for those who were anti-Thomas to change their opinion about Thomas' confirmation, one would expect a general shift away from Thomas as the disconfirming evidence eventually affects some of the pro-Thomas people.

Reactions to inconsistencies can sometimes be influenced by the way in which information is presented. If the problem can be reframed to make the inconsistencies obvious, it appears that people are more likely to resolve them. For example, they might change a previously held belief. Consider the results from the following questions that we posed in mid-October 1991, shortly after the weekend hearings but before confirmation of the Thomas nomination.

We asked students in a class at the Weatherhead School of Management if they would vote to confirm Thomas' nomination. All responses were obtained on self-administered and anonymous questionnaires. They voted to confirm Thomas (eight in favor, seven against, and two abstentions). We then posed two questions to them:

Assume that you were designing a procedure to select a Supreme Court Justice. As part of the process you must make a selection between two candidates. Pool One contains 'Perjurers' (those who will lie under oath), while Pool Two contains 'Truth Tellers' (those who will only tell the truth under oath). 
Question 1: What is the highest subjective probability that you would tolerate that your selection would come from Pool 1 (perjurers)?

Question 2: What is your subjective probability that Clarence Thomas committed perjury?"

The purpose of these questions was to frame the issue such that they would view the candidate according to how well he met their own preestablished criterion. This should highlight inconsistencies in favor of the criterion.

Their median acceptable level for selecting from the perjury pool was $13 \%$. Their median probability that Thomas was a perjurer was $45 \%$. Then we asked the students to vote again. This time, they voted to reject (6 'yes' to 11 'no'). So, some people changed their minds when the problem was framed in terms of general beliefs about truth telling.

Of course, one may believe that these results occur because people do not like to appear foolish on a survey. But is such behavior limited to survey situations? We think not. In general, people do not like to appear foolish to others or to themselves. Over time, selective perception of facts relevant to a situation may fail to provide adequate protection against appearing to be foolishly inconsistent. And, there continued to be mass media information about this case over the time period in question. Doubts might surface for some people and cause them to go through a dissonance reduction process.

Another reasonable prior expectation is that women might have been more likely to believe the evidence from Anita Hill. The data summarized by Rucinski suggests that changes were greater among the women than among the men. Of those women who were initially pro-Thomas, about $30 \%$ abandoned this position. The corresponding change for the men was about $22 \%$. This difference in the male and female changes was statistically significant $(\mathrm{Z}=3.98 ; \mathrm{p}<.0001)^{2}$

\section{Expectations about Methodological Issues}

Might the differences in the 1991 and 1992 poll results be better explained by differences in the polling methods used? Rucinski reviews a number of methodological issues. In doing so, she makes the results more

\footnotetext{
${ }^{2}$ We assumed that the sample size was equal to the number in the 1992 surveys (much less than those in the 1991 surveys), so this was a conservative assumption. On the basis of figures for the 1991 surveys reported in Mansbridge and Tate (1992) we assumed that $47 \%$ of the respondents were male. This yielded 1988 females and 1763 males. Initially, it was estimated that $47 \%$ of the females (882) were pro-Thomas, while $55 \%$ of the males (1032) were pro-Thomas. In 1992, 30\% of the females and $43 \%$ of the males were. About $30 \%$ of the females changed their opinions, and $22 \%$ of the males changed.
} 
interpretable because a rich body of evidence exists about the effects of different survey procedures. We consider some of the issues here.

The 1991 polls were based mostly on weekend surveys, while the 1992 surveys were not. What effect might one have expected from this difference a priori? According to Traugott (1987), weekends are relatively more likely to have a higher proportion of respondents who are Democrats (as compared with weekday polls). This factor is likely, therefore, to reduce pro-Thomas replies for the 1991 surveys, an effect that would in turn reduce the magnitude of the opinion change.

Another possible explanation for differences is sponsorship, which might, for example, lead one to expect more pro-Thomas replies in the Wall Street Journal polls. This was not the case. The Wall Street Journal's polls tended to report fewer pro-Thomas opinions.

Response rates are another factor often proposed to explain differences in polls. In general, one expects those with less interest in an issue to be less likely to respond. A higher response rate should draw in more of those with low or marginal interest, and this should produce more "no opinions." As it turned out, "no opinions" were about $21 \%$ in both the 1991 and 1992 surveys, suggesting that response rates did not have a strong effect.

The wording of the questions did seem to have an impact. Note from Appendix B in Rucinski that the question "Whom do you believe more?" drew more pro-Thomas responses than did "Which is telling the truth?", perhaps because some respondents may have decided that neither was telling the truth (53\% to $50 \%$ in $1991 ; 39 \%$ to $34 \%$ in 1992). Whereas the former question was used in $54 \%$ of the 1991 surveys, it was used in $67 \%$ of the 1992 surveys. If question-wording explains the differences observed, this change should have produced more pro-Thomas responses in the 1992 surveys.

Rucinski expressed a concern that the order in which questions were asked might affect the respondents, observing that asking the confirmation question first "may have affected responses to the credibility items ... if respondents reported favoring confirmation and wanted to give consistent credibility responses (p. 585).” In our October 1991 study, we found this to be so. Respondents were far more likely to judge Thomas a perjurer if they had not already been asked about their overall opinion regarding the Thomas nomination. A group of $26 \mathrm{MBAs}, 2 / 3$ of whom were males, were asked the single question "What is your subjective probability that Clarence Thomas committed perjury?" Their median probability estimate that Thomas was a perjurer was $92 \%$. Similarly, for a group of 20 undergraduates, half male, there was also a $92 \%$ median probability. These estimates were substantially larger 
than the $45 \%$ estimate that was obtained when subjects were first asked whether they favored Thomas for the appointment.

The fact that different polling organizations used different procedures provides some assurance against methodological shortcomings. That is, if these procedures had large effects on the reported attitudes, it would be less likely to find much agreement among the polls. In fact, the polls showed much agreement. A reasonable strategy for handling the effects of potential biases is to combine the results from the various surveys.

\section{Conclusions}

If disconfirming evidence has long-term effects, and if people attempt to reconcile inconsistencies in their beliefs, then one would expect to find attitude changes reflected by the polls. When we framed the problem by having people set their criteria before declaring their opinions about Thomas, we observed some immediate restructuring of opinions about Thomas. When this restructuring is left to time, we would expect little short-term change, but some long-term change. The change observed in the Thomas polls was consistent with this expectation.

It is important that reports of polls include information about the polling procedures, such as sponsorship, wording of questions, polling times, and nonresponse rates. Rucinski successfully gathered such information, despite encountering difficulties. By doing so, and by more fully disclosing it, she has made it easier to interpret changes in public opinion regarding the Thomas nomination. This is because a rich body of evidence exists about the effects of various survey research methods. In this case, then, the changes over time were consistent with prior expectations and an examination of the methodological issues supported this conclusion.

In general, we believe that polls do allow for interpretations about attitude changes. The interpretation of changes can be aided to the extent that one has theory or prior expectations to explain attitude changes, where the polling organizations report on the key methodological aspects, and where results from alternative polls can be combined. 


\section{References}

Batson, C. D. (1975), "Rational Processing or Rationalization? The Effect of Disconfirming Information on a Stated Religious Belief.” Journal of Personality and Social Psychology 32:176-184.

Buchanan, W. (1986), “Election Predictions: An Empirical Assessment.” Public Opinion Quarterly 50:222-227.

Cialdini, R. B. (1993), Influence. New York: William Morrow.

Lau, R. R. (1994), “An Analysis of the Accuracy of 'Trial Heat' Polls During the 1992 Presidential Election.” Public Opinion Quarterly 58:2-20.

Mansbridge, J. and K. Tate (1992), "Race Trumps Gender: The Thomas Nomination in the Black Community.” PS: Political Science \& Politics 25:488-492.

Mayer, J. and J. Abramson (1994), Strange Justice: The Selling of Clarence Thomas. Boston: Houghton Mifflin.

Rucinski, D. (1993), "Rush to Judgment? Fast Reaction Polls in the Anita Hill- Clarence Thomas Controversy.” Public Opinion Quarterly 57: 575-592.

Traugott, M. W. (1987), “The Importance of Persistence in Respondent Selection for Preelection Surveys.” Public Opinion Quarterly 51:48-57.

Webster, E. C. (1964), Decision Making in the Employment Interview. Montreal: Eagle. 